\title{
LA DIMENSIÓN ORGÁNICA DE LA JUSTICIA CONSTITUCIONAL: APUNTES PARA LA REFLEXIÓN A PARTIR DE LA COMPARACIÓN DE LOS CASOS ITALIANO Y ESPAÑOL
}

\section{The organic dimension of Constitutional Justice: notes for reflection based on the comparison of Italian and Spanish cases}

\author{
LAURA BAAMONDE GÓMEZ \\ Universidad Carlos III de Madrid \\ lbaamond@der-pu.uc3m.es
}

Cómo citar/Citation

Baamonde Gómez, L. (2019).

La dimensión orgánica de la Justicia constitucional: apuntes para la reflexión

a partir de la comparación de los casos italiano y español. Anuario Iberoamericano de Justicia Constitucional, 23(2), 339-367.

doi: https://doi.org/10.18042/cepc/aijc.23.10

\section{Resumen}

Aproximación a la configuración constitucional del mandato de los magistrados constitucionales españoles e italianos, tratando de observar las similitudes y diferencias en la regulación en ambos modelos. La finalidad de dicha comparación es la de poder extraer conclusiones acerca de las fortalezas y debilidades de los diseños institucionales implantados en sendos contextos, con el ánimo de aportar propuestas de mejora en aquellos aspectos que a pesar de las reformas siguen siendo problemáticos.

Una vez determinada la importancia de parangonar los casos italiano y español, la exposición se dividirá en tres partes: aspectos problemáticos de la composición, dificultades en la aplicación de las previsiones temporales y estatuto jurídico de los magistrados constitucionales. A su vez, cada apartado será estudiado a partir de la dicotomía fisiología/patología. 


\section{Palabras clave}

Jueces; tribunales constitucionales; Italia; España.

\section{Abstract}

Approach to the constitutional configuration of the mandate of the Spanish and Italian constitutional judges, trying to observe the similarities and differences in the regulation in both models. The purpose of this comparison is to be able to draw conclusions about the strengths and weaknesses of the institutional designs implemented in the two contexts, with the aim of providing proposals for improvement in those aspects that despite the reforms remain problematic.

Once the importance of matching the Italian and Spanish cases has been determined, the exposition will be divided into three parts: problematic aspects of the composition, difficulties in applying the temporary provisions and legal status of the constitutional judges. At the same time, each section will be studied from the physiology/pathology dichotomy.

\section{Keywords}

Judges; Constitutional Courts; Italy; Spain. 


\section{SUMARIO}

I. INTRODUCCIÓN: EL INTERÉS DE UN ESTUDIO COMPARADO ESPAÑA-ITALIA. II ASPECTOS PROBLEMÁTICOS DE LA COMPOSICIÓN DEL COLEGIO. III. DIFICULTADES PARA LA APLICACIÓN AUTOMÁTICA DE LAS PREVISIONES SOBRE LA DURACIÓN DEL MANDATO. IV. PRERROGATIVAS Y RESTRICCIONES DERIVADAS DEL EJERCICIO DE LA MAGISTRATURA CONSTITUCIONAL. V. CONCLUSIONES. BIBLIOGRAFíA.

\section{INTRODUCCIÓN: EL INTERÉS DE UN ESTUDIO COMPARADO ESPAÑA-ITALIA}

El estudio de los aspectos orgánicos de la magistratura constitucional podría resultar, al menos a priori, una cuestión baladí, excesivamente técnica y carente de relevancia doctrinal. Sin embargo, a través de las líneas que siguen intentaré demostrar lo erróneo de tal premisa. Pues la forma que adopte la configuración del órgano de cierre de un sistema democrático es una cuestión estrechamente vinculada a la propia legitimación constitucional de tal institución, aspecto no menor, si tenemos en cuenta la naturaleza contramayoritaria de la Justicia constitucional. Baste como ejemplo observar la realidad sociopolítica española de los últimos años. En un contexto generalizado de crisis institucional el Tribunal Constitucional no fue ajeno a la crítica, y, como bien puede consultarse en las hemerotecas, fue reiteradamente cuestionado.

Partiendo de ese escenario, vengo considerando desde hace años la necesidad de arrojar luz y contribuir a explicar una institución fundamental en la consolidación democrática de nuestro país, a través de la reivindicación de la dignidad de sus miembros. Juristas todos ellos de reconocido prestigio cuyos servicios no suelen ser reconocidos, sino más bien malinterpretados en términos partidistas, con el consecuente descrédito personal e institucional que ello implica.

De ahí mi interés en estudiar los aspectos problemáticos que genera la aplicación práctica de las normas que disciplinan el mandato de los jueces constitucionales, y con ello poder reflexionar acerca de cómo redefinir ese marco normativo en aras de garantizar un mejor contexto para el sereno desempeño de las funciones del cargo. Contribuyendo así a favorecer una mejor 
comprensión social de la trascendental labor del órgano, crucial como máximo intérprete en materia de garantías constitucionales, y de sus titulares.

Afronto así una aproximación a la configuración constitucional del mandato de los magistrados del Tribunal Constitucional español y de la Corte Constitucional italiana. Tratando de observar las similitudes y diferencias en la regulación de esta cuestión en ambos modelos, con la finalidad de extraer conclusiones acerca de las fortalezas y debilidades de los diseños institucionales en materia de mandato de los jueces constitucionales implantados en sendos contextos ${ }^{1}$.

La selección de los casos de Italia y España no es fruto de la casualidad. Pues en ambos supuestos estamos ante exponentes del modelo mixto de Justicia constitucional, surgido en la Europa continental de la II posguerra mundial a partir de la hibridación de los modelos puros o ideales americano y kelseniano, respectivamente. Si bien la antigüedad de sendos órganos de jurisdicción constitucional es bien distinta, pues la Corte Constitucional italiana inicia su andadura efectiva en 1956 y el Tribunal Constitucional español, sin embargo, data del más reciente 1980, no es menos cierto que en ambos casos nos encontramos dentro de la misma categoría genérica aludida y en coyunturas de génesis del modelo similares de transición a la democracia tras períodos de dictadura (fascismo en el primer caso y franquismo en el segundo) caracterizados por una fuerte transgresión de los derechos fundamentales.

Es un hecho, por tanto, que la implantación del Estado constitucional en Italia fue mucho más temprana que en España, de ahí que el Tribunal Constitucional español —al igual que la Constitución española en su conjuntotuviese como fuente de inspiración en el momento de su surgimiento - $\mathrm{y}$ en su posterior desarrollo- aquellos ejemplos más destacados y consolidados que ofrecía el derecho comparado, a saber: Alemania e Italia.

En el anhelo de crear un tribunal constitucional, que sin renunciar a la inspiración de su precedente Tribunal de Garantías Constitucionales de la II República, superase los déficits de configuración que este había presentado en su corta vida, el constituyente español optó por el esquema italiano de selección, mandato y estatuto de sus jueces constitucionales como referencia. Y aquí reside la razón de haber querido trazar la comparación entre ambos países.

Así, trataré de confrontar — de manera sucinta—los modelos italiano y español, a partir, a su vez, de la dicotomía fisiología/patología, con la finalidad

1 Un estudio completo y pormenorizado de las cuestiones analizadas en el presente artículo puede encontrarse en mi monografía La magistratura constitucional en España e Italia. Selección, aspectos temporales del mandato y estatuto jurídico (Baamonde, 2019). 
de discernir, de un lado, el «deber ser» que imponen las normas objeto de análisis, y, del otro, el «ser» de su aplicación práctica.

Parangonar los aspectos orgánicos del Tribunal Constitucional español con su homólogo italiano resulta entonces de especial interés en la medida en que permite contextualizar las diferencias — que las hay-, en atención a las especificidades de las culturas jurídicas respectivas, y a la más dilatada experiencia constitucional italiana. Una andadura mayor, muy útil a la hora de analizar los principales retos a los que se enfrenta la Justicia constitucional actual en términos de legitimidad, imagen pública y credibilidad. Así, la marcada diferencia de «edad» entre la Corte y el Tribunal será un factor decisivo en el objetivo de someter a crítica al joven modelo español a la luz de la rica experiencia italiana, ampliamente estudiada por su doctrina.

\section{ASPECTOS PROBLEMÁTICOS DE LA COMPOSICIÓN DEL COLEGIO}

Entrando ya en el fondo, y para poder comprender cuáles son los aspectos problemáticos relacionados con la selección de los magistrados constitucionales, es necesario abordar esta cuestión desde una perspectiva fisiológica. Para ello, describiré de manera muy sintética los diseños institucionales español e italiano al respecto.

El cuadro normativo que dibuja el modelo de designación de los magistrados del Tribunal Constitucional español viene determinado por el art. 159.1 CE, en conexión con los apartados primero y segundo del art. 16 LOTC $^{2}$, y se resume de forma esquemática en elección de cuatro magistrados por parte del Congreso de los Diputados, otros cuatro por el Senado (entre las propuestas formuladas por las Asambleas legislativas de las comunidades autónomas), dos a propuesta del Gobierno, y los dos restantes por decisión del Consejo General del Poder Judicial.

2 Art. 159. 1 CE: «El Tribunal Constitucional se compone de 12 miembros nombrados por el Rey; de ellos, cuatro a propuesta del Congreso por mayoría de tres quintos de sus miembros; cuatro a propuesta del Senado, con idéntica mayoría; dos a propuesta del Gobierno, y dos a propuesta del Consejo General del Poder Judicial»; art. 16 LOTC: «1. Los Magistrados del Tribunal Constitucional serán nombrados por el Rey, a propuesta de las Cámaras, del Gobierno y del Consejo General del Poder Judicial, en las condiciones que establece el art. 159. 1 de la Constitución. 2. Los magistrados propuestos por el Senado serán elegidos entre los candidatos presentados por las Asambleas Legislativas de las Comunidades Autónomas en los términos que determine el Reglamento de la Cámara». 
A tenor de estos preceptos, se puede afirmar que el Tribunal Constitucional es el único órgano del Estado en cuyo nombramiento intervienen, de forma directa o indirecta, prácticamente todos los demás poderes del Estado.

Destaca el ligamen - aunque indirecto - con la voluntad popular, pues tanto las Cámaras parlamentarias como el Gobierno vendrán determinados por el resultado de las urnas. Participa también el poder moderador, puesto que la formalidad del nombramiento recae en la figura del jefe de Estado. De forma directa, intervienen los poderes ejecutivo, parlamentario y judicial, pues a ellos atribuye la Constitución la competencia para la designación de los doce magistrados constitucionales (De Esteban y González Trevijano, 1994: 177-178). Finalmente, y en virtud de la reforma del art. 16. 1 in fine LOTC, operada por la LO 6/2007, el poder autonómico también cuenta con una más que notable participación en la elección de candidatos que corresponde al cupo del Senado.

La opción del constituyente por un modelo de origen plural de las propuestas ha sido valorada, en términos generales, de forma positiva - otra consideración merecerá la concreta distribución de los candidatos a elegir entre los distintos actores, así como la mecánica seguida en la práctica para la formación de su voluntad- En este orden de cosas, se ha resaltado su plus de legitimidad democrática ${ }^{3}, y$, asimismo, se ha significado la contribución del modelo de elección al reforzamiento de la dignidad y a la acentuación del papel integrador del Tribunal Constitucional (García Pelayo, 1981: 29).

A partir de la descripción trazada del sistema de designación, cualquier observador atento habrá caído en la cuenta del excesivo peso de los órganos de índole política en el nombramiento de los magistrados. Habida cuenta de la caracterización del Gobierno como emanación de la mayoría parlamentaria, y teniendo presente el mecanismo de designación de los vocales del Consejo General del Poder Judicial — las propuestas proceden del Congreso y el Senado- no es aventurado afirmar que estamos ante una curiosa paradoja: la inmensa mayoría de los miembros del órgano controlador deben su nombramiento a las candidaturas formuladas por aquellos órganos a los que debe controlar (Fernández Segado, 1999: 80-81).

3 Ibid., p. 178. El déficit de legitimidad democrática suele ser una crítica habitual hacia la Justicia constitucional en otros países. En España, podrán objetarse numerosos aspectos del modelo de designación perfilado en la Constitución —en esta línea discurrirá mi discurso a renglón seguido-, no obstante, dada la preponderancia del Parlamento en la elección de magistrados, la satisfacción del principio democrático parece, al menos formalmente, garantizada. 
La necesidad de contar con mayorías reforzadas en la elección que corresponde a las Cámaras parlamentarias — tres quintos- (art. 159.1 CE), así como, por previsión legal, en la que compete al Consejo General del Poder

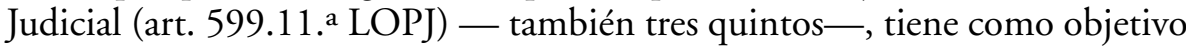
incentivar un amplio acuerdo entre las fuerzas parlamentarias. Lo que se persigue, por lo tanto, es evitar que el partido que goce de la mayoría parlamentaria en el momento de la elección pueda acaparar de manera monopolística las candidaturas. Sin duda, esta garantía, al menos formalmente, tiende a rebajar la carga política que suele caracterizar el proceso de nombramiento, tratando de que prevalezcan las consideraciones de índole técnica frente a las puramente partidistas. Lo que redundará, en todo caso, en una mayor independencia del Tribunal Constitucional, puesto que sus miembros gozarán de un gran respaldo, y, por lo tanto, no serán cuestionados, al menos a priori. Sin embargo, las buenas intenciones subyacentes a esta exigencia pueden desdibujarse cuando observamos esta garantía con más detalle.

De una parte, la operatividad de este freno se reduce a las propuestas que efectúan el Congreso y el Senado, pues la exigencia de mayoría en el caso del órgano de gobierno de los jueces, como ya ha quedado apuntado, no deriva de la Constitución, sino de una previsión de rango legal, y que, por consiguiente, puede ser modificada, o directamente eliminada, por el legislador. Asimismo, los dos magistrados designados por el Gobierno quedan fuera de esta garantía, como es lógico. En conclusión, este freno, cuya importancia no debe ser ignorada, tiene un radio de acción limitado.

De otra parte, el segundo problema que plantea la exigencia de mayorías reforzadas, y el necesario acuerdo parlamentario que esto conlleva, es el fomento de retrasos en la renovación de las vacantes. Un nada desdeñable inconveniente que se abordará en el siguiente epígrafe.

La cualificación técnico-jurídica, en combinación con un mínimo período de ejercicio profesional, es otro de los aspectos que mejor pueden contribuir a equilibrar el excesivo peso de los órganos políticos en la elección de los jueces constitucionales. Es por ello que tanto el constituyente como el legislador orgánico han incluido toda una serie de previsiones con objeto de «objetivar» en lo posible las consideraciones que rigen a la hora de proponer candidatos a integrar el Pleno del Tribunal Constitucional. Así, los arts. 159. 2 CE y 18 LOTC $^{4}$, respectivamente, disponen una serie de condiciones de elegibilidad que pueden ser clasificadas de la siguiente manera:

4 Art. 159. 2 CE: «Los miembros del Tribunal Constitucional deberán ser nombrados entre Magistrados y Fiscales, Profesores de Universidad, funcionarios públicos y Abogados, todos ellos juristas de reconocida competencia con más de quince años 
- Requisitos generales: ciudadanía española, plena capacidad, no incompatibilidad (arts. 18, 19 y 23.1 LOTC).

- Requisitos especiales: perfil profesional, juristas de reconocida competencia, plazo temporal mínimo de ejercicio profesional o en activo (arts. 159.2 CE y 18 LOTC).

Por su parte, el art. 135 coma 1 de la Constitución italiana determina que la Corte Constitucional viene compuesta por quince jueces, distribuyendo su selección — por tercios — de la siguiente manera: cinco de ellos vendrán elegidos por el presidente de la República, otros cinco por el Parlamento en sesión conjunta, y los cinco restantes, por las Supremas Magistraturas ordinaria y administrativa ${ }^{5}$.

Dibujó así el constituyente italiano un esquema de composición tripartita que sirvió de inspiración — bastantes años más tarde - al español. No obstante, y a pesar de las grandes similitudes que cabe apreciar a primera vista, es de justicia señalar que ambos modelos, aun pareciéndose bastante, presentan ciertas diferencias, que responden, sin duda, a los diversos contextos político-institucionales en que fueron adoptados.

El constituyente italiano —al que trató de seguir años más tarde el español- configuró un modelo de composición tripartita con el objetivo de garantizar la legitimación de un órgano cuya lógica contramayoritaria lo hace especialmente vulnerable a la crítica. En estas circunstancias, la intervención de los diversos poderes del Estado en su integración responde a la intención de hacer convivir en su seno una tríada de dimensiones o perspectivas que son cruciales en atención a las altas funciones que la Corte Constitucional está llamada a desempeñar. Así, la garantía jurisdiccional de la Constitución estaría compuesta de una visión jurídico/judicial representada por las Supremas Magistraturas $^{6}$; de una visión política correspondiente a los nombramientos

de ejercicio profesional»; art. 18 LOTC: «Los miembros del Tribunal Constitucional deberán ser nombrados entre ciudadanos españoles que sean Magistrados, Fiscales, Profesores de Universidad, funcionarios públicos o Abogados, todos ellos juristas de reconocida competencia con más de quince años de ejercicio profesional o en activo en la respectiva función».

5 Art. 135 coma $1 \mathrm{CI}$ : «La Corte costituzionale è composta di quindici giudici nominati per un terzo dal Presidente della Repubblica, per un terzo dal Parlamento in seduta comune e per un terzo dalle supreme magistrature ordinaria ed amministrative».

6 Acerca de la importancia de este poder de nominación en favor de las Supremas Magistraturas y su rol fundamental para mantener una proporcionalidad adecuada en la presencia de jueces constitucionales procedentes de la magistratura, véase Aloisio (2004: 197). 
de origen parlamentario, y de una visión institucional (política de nuevo, pero imparcial) en relación con la propuesta de candidatos concerniente al presidente de la República (Zagrebelsky, 1988: 94-95)7.

Al igual que sucedía cuando nos referíamos al ordenamiento español, el constituyente y el legislador italianos han sido muy conscientes de los peligros de una composición de la Corte Constitucional excesivamente condicionada por factores político-partidistas, cuando no monopolizada por la mayoría parlamentaria de turno. Y, por este motivo, no debe extrañar la inclusión de mayorías cualificadas en las designaciones de base colegial.

Tanto la elección por parte del Parlamento en sesión conjunta como la correspondiente a las Supremas Magistraturas se caracterizan por exigir la obtención de mayorías reforzadas que impidan situaciones en las que la fuerza o fuerzas políticas predominantes se puedan hacer con todo el reparto, y poner en duda la independencia del órgano como conjunto y la imparcialidad de los jueces constitucionales individualmente considerados. Así, ante la necesidad de garantizar la legitimación de la Corte y la consecuente aceptación de sus resoluciones, se introduce esta suerte de herramientas que obligan a los actores implicados en la decisión a llegar a acuerdos sobre los candidatos. Un debido consenso que tiende a neutralizar las candidaturas excesivamente escoradas desde un punto de vista partidista, por ser inaceptables en la negociación con las demás fuerzas, y fomentar la propuesta de personalidades más ponderadas.

Asimismo, cabe destacar un aspecto nada baladí, y es el hecho de introducir mecanismos flexibilizadores o facilitadores del acuerdo, como la posibilidad de realizar votaciones sucesivas en las que bastaría la obtención de mayorías menos rigurosas o el recurso a escrutinios de ballotage entre los candidatos más votados. Un aspecto no previsto por el ordenamiento español, y que a priori podría resultar interesante para el desbloqueo de situaciones en las que la falta de acuerdo pueda conllevar un retraso en la renovación del órgano.

Antes de dar por finalizado el esquema de integración de la Corte Constitucional italiana, debe recordarse, por motivos de completitud, la existencia de una situación en que la composición de la Corte varía respecto de lo referido anteriormente. Más concretamente, se amplía. El apartado séptimo del art. 135 de la Constitución italiana establece la llamada "Corte integrada" para los casos en que esta deba ejercer competencias de Justicia penal constitucional en los procesos contra el presidente de la República. En estas coyunturas, además de los quince jueces que componen el plenum, intervienen dieciséis miembros elegidos por sorteo entre un elenco de ciudadanos en posesión de los requisitos exigidos para ser elegido senador, una relación elaborada por el Parlamento cada nueve años mediante votación bajo las mismas condiciones mencionadas respecto de los jueces constitucionales ordinarios. 
En todo caso, el esquema tripartito de composición previsto en la Constitución italiana no presenta una preferencia tan clara por los jueces de origen directo o indirecto en el terreno político como el español, sino que se caracteriza por un mayor equilibrio entre los componentes político y técnico. En esta dirección se sitúa la intervención del presidente de la República como «equilibrador» o garante del pluralismo, y para incidir en esta condición el art. 1 de la Ley número 87 de 11 de marzo de 1953 estableció que la selección de los quince miembros de la Corte tendrá lugar in ordine succesivo, cinco por parte de las Supremas Magistraturas ordinaria y administrativa, cinco por parte del Parlamento en sesión conjunta, y finalmente los cinco restantes por parte del presidente de la República.

La reserva de la elección presidencial para el final del orden cronológico no es, por lo tanto, casual, sino que refuerza el papel de este como árbitro o moderador, en este caso, en atención a su competencia designante ${ }^{8}$. Pues su facultad discrecional para la propuesta de candidatos en ningún caso se ve turbada por la injerencia del Gobierno, una costumbre constitucional ampliamente señalada y alabada por la doctrina italiana.

Como último freno a la politización en relación con la composición, es menester comentar —al igual que sucedía en el modelo español- los requisitos de elegibilidad previstos por el ordenamiento italiano para acceder al cargo de juez constitucional. De nuevo su finalidad es precisamente la de contrapesar o compensar los criterios de afinidad político-partidista que eventualmente determinaron la designación de alguno de los candidatos.

$\mathrm{El}$ art. 135 de la CI en su apartado segundo9 contiene una formulación cuyo tenor recuerda, no por casualidad, a la establecida por el constituyente es-

8 Acerca de la importancia del rol equilibrador del presidente de la República en conexión con la obligación de respetar el orden sucesivo en las designaciones, véanse D’Orazio (s.f.: 259) y Adamo (2014: 4-7). En esta última obra se hace una precisión de interés respecto de cuestiones que se verán en el próximo apartado. Pues si bien los cambios producidos en el ordenamiento italiano respecto de las normas que disciplinan los aspectos temporales de la renovación de la Corte han desdibujado la importancia del orden sucesivo en la selección — debido a que la prevalencia del mandato individual tiende a distanciar en el tiempo la provisión de vacantes frente al modelo de renovación contextual de los tercios-, esta no puede considerarse obsoleta, pues habrá situaciones donde coincidan en el tiempo dichas vacancias y en ese caso la función equilibradora atribuida a los nombramientos de origen presidencial solo queda garantizada con el respeto al orden constitucionalmente establecido.

9 Art. 135 coma 2 CI: «I giudici della Corte costituzionale sono scelti fra i magistrati anche a riposo delle giurisdizioni superiore ordinaria ed amministrative, i professori ordinari di università in materia giuridiche e gli avvocatti dopo venti anni d'esercizio». 
pañol en su art. 159.2, disponiendo que los quince miembros de la Corte Constitucional serán elegidos entre magistrados, incluso a riposo ${ }^{10}$ de las Supremas Magistraturas ordinaria y administrativa, profesores ordinarios ${ }^{11}$ de universidad en disciplinas jurídicas y abogados tras veinte años de ejercicio profesional.

La opción del constituyente por hacer posible la presencia de estas profesiones en el interior de la Corte tiene la virtualidad de hacer convivir tres diversas sensibilidades o perspectivas en el estudio del derecho, todas ellas enriquecedoras para la tarea que están llamados a desempeñar los futuros jueces constitucionales.

Una vez analizada la dimensión fisiológica, corresponde aludir a aquellos aspectos patológicos o susceptibles de revisión, derivados de la aplicación práctica del marco normativo. Así, pueden destacarse fenómenos como la lottizzazione en el reparto de candidaturas, los efectos derivados de los vetos mutuos, la percepción de partidización de los jueces, el pernicioso «etiquetado público» y el estimulante debate acerca del carácter no representativo del mandato constitucional y sus implicaciones en los diseños de participación de entes subestatales en la provisión de candidatos.

Merece la pena subrayar que los constituyentes italiano y español han optado precisamente por un sistema de composición tripartita, con intervención de los diversos poderes del Estado. No obstante, en este punto, muestro una mayor afinidad con el primer modelo en la medida en que resulta más equilibrado. Debe recordarse, sin embargo, que en el caso español la preponderancia de la mayoría parlamentaria es mucho más destacada. La atribución de la propuesta de ocho candidatos al Parlamento viene unida a la de dos ulteriores candidaturas correspondientes a un Gobierno cuyo presidente lo es en virtud de la relación de confianza que la mayoría del Congreso de los Diputados le ha otorgado. Los dos magistrados restantes son elegidos por el Consejo General del Poder Judicial, cuyos veinte vocales son elegidos, a su vez, por las Cámaras.

Considero que el constituyente español debería haber sido más fiel al modelo ideal (el italiano), en cuanto, si bien aparentemente sendos ordenamientos parecen confiar la elección de los jueces constitucionales a los diversos poderes del Estado, en el caso español, el resultado semeja particularmente escorado a las consideraciones políticas, o mejor dicho, partidistas. Así, la solución italiana, orientada a mantener un equilibrio en la composición entre las consideraciones políticas (un tercio del Parlamento) y las consideraciones de tipo técnico (un tercio de las Supremas Magistraturas) y un equilibrio

10 Jubilados.

11 Categoría académica más elevada, equivalente al catedrático español. 
institucional (un tercio del presidente de la República) resulta mucho más interesante en términos de legitimación del órgano, en tanto que se aprecia un evidente vínculo de este con la soberanía popular, lo que permite afrontar cualquier objeción antidemocrática sin dejar la totalidad de las candidaturas en manos de los partidos políticos, que frecuentemente en los procesos de selección anteponen sus propios intereses a aquellos del Estado. De tal manera, la intervención de las Supremas Magistraturas, en nada comparable a la de nuestro Consejo General del Poder Judicial, resulta más convicente como instrumento idóneo en la aportación de una visión técnica a un órgano cuyas funciones son de carácter jurisdiccional y no político. Por tanto, una propuesta más próxima al modelo italiano podría consistir en la atribución de la selección correspondiente al Poder Judicial a un órgano jurisdiccional del máximo nivel, como, por ejemplo, la Sala de Gobierno o la Sala Especial del art. 61 LOPJ del Tribunal Supremo, haciendo así preponderante la sensibilidad judicial en detrimento de aquella otra de índole política.

Respecto a la intervención del Jefe del Estado en la formulación de un tercio de las propuestas, resulta óptima la práctica llevada a cabo en Italia, pero que, por razones obvias, no es susceptible de recepción en España. Sin embargo, la nueva situación política de ruptura del tradicional bipartidismo hegemómico podría crear nuevos escenarios en la selección de candidatos que corresponde al Gobierno. La eventual dificultad de los grandes partidos en la consolidación de mayorías suficientes para poder gobernar en solitario y la consiguiente necesidad de coaligarse o suscribir pactos de gobernabilidad pueden aportar nuevas estrategias también en este punto.

Por lo que concierne a las candidaturas de origen parlamentario, debe ponerse el foco de atención sobre la importancia de los mecanismos que atenúan la parcialidad característica de los procesos de selección, y que, consecuentemente, derivan en el pernicioso «etiquetado» de los jueces por parte de la opinión pública, en función de cuál haya sido el grupo político que haya sustentado su candidatura. Es por ello que debo insistir en la utilidad de las mayorías reforzadas, siempre que evite en la medida de lo posible el recurso a un sistema de cuotas. Un retorno al consenso genuino en sede de asignación de las vacantes sería altamente deseable. Obtener un apoyo, sino unánime, al menos particularmente amplio por la totalidad de los candidatos sería la mejor carta de presentación de estos en su ingreso en el colegio.

Además del origen político de algunas candidaturas, tanto en España como en Italia, se ha discutido intensamente la posibilidad de que los entes regionales participen de la selección de los magistrados constitucionales, llegando en el caso español a materializarse una modificación legislativa al respecto. Acerca de esta cuestión, mi opinión es favorable a la doctrina mayoritaria en Italia, en la medida en que considero que una intervención directa de los te- 
rritorios podría poner en duda la naturaleza del mandato de los jueces, que en ningún caso puede ser considerado representativo. Mantengo, por tanto, que la mejor solución sería de carácter orgánico. Tanto en el caso español como italiano, los respectivos Senados forman parte de la selección de una parte de los candidatos. En sendos contextos, la crítica a la falta de sensibilidad territorial de la Justicia constitucional deriva de la escasa caracterización de estas Cámaras como representantes de los territorios. De ahí que la solución idónea fuese la redefinición de las mismas en sentido federal.

\section{DIFICULTADES PARA LA APLICACIÓN AUTOMÁTICA DE LAS PREVISIONES SOBRE LA DURACIÓN DEL MANDATO}

El mismo enfoque del apartado precedente puede aplicarse a los aspectos temporales del mandato. De tal manera, tras la referencia a los modelos ideales italiano y español — señalando con especial atención las modificaciones sufridas en el sistema de renovación del primero en el año 1967- se desglosan aquellos efectos no deseados que la realidad nos brinda.

Es la propia Constitución española en su art. 159. 3 CE la que determina la duración del mandato de los magistrados constitucionales: «Los miembros del Tribunal Constitucional serán designados por un período de nueve años [...]». En los mismos términos se pronuncia el art. 16. 3 de la Ley Orgánica del Tribunal Constitucional (en adelante, LOTC): «La designación para el cargo de Magistrado del Tribunal Constitucional se hará por nueve años [...]».

La elección de un período prolongado de desempeño del cargo - nueve años - ha merecido una valoración altamente positiva por parte de la doctrina. El hecho de que se haya apartado la renovación del Tribunal Constitucional de la lógica de las legislaturas constituye un importante factor para garantizar la independencia de sus miembros. Sobre todo, teniendo en cuenta que las Cámaras Parlamentarias, además de ser los órganos productores de las leyes cuya constitucionalidad deberán enjuiciar, son también partícipes privilegiados de su elección ${ }^{12}$.

Además de la virtualidad de esta garantía respecto de la independencia, se han apuntado otros efectos beneficiosos, derivados de la estancia prolongada en el cargo de juez constitucional. Por ejemplo, Jorge de Esteban y Pedro

12 Sobre la relación entre mandatos prolongados e independencia de los magistrados, véanse García Pelayo (1981: 29), Fernández Segado (1999: 106-109; este autor incluye esta garantía dentro de los llamados «frenos frente a la politización»); De Esteban y González Trevijano, (1994: 181), y Almagro Nosete (1989: 107). 
González Trevijano han defendido que el período de nueve años favorece la existencia de un elemento de continuidad, necesario para la estabilidad y coherencia de la jurisprudencia del Tribunal (1994: 181).

Esa previsión de nueve años correspondería con la duración ordinaria del mandato. A la que deberíamos añadir lo que dispone la LOTC en su art. 17. 2, al prever el instituto de la prorogatio, cuando dice: "Los Magistrados del Tribunal Constitucional continuarán en el ejercicio de sus funciones hasta que hayan tomado posesión quienes hubieren de sucederles». El objetivo de esta disposición es, obviamente, garantizar la continuidad de las tareas que corresponden al Tribunal.

En cuanto a las posibilidades de reelección en el cargo, esta no está totalmente vedada, pero sí limitada, aunque con alguna excepción. El art. 16. 4 LOTC determina: «Ningún Magistrado podrá ser propuesto al Rey para otro período inmediato, salvo que hubiera ocupado el cargo por un plazo no superior a tres años». Esta restricción ${ }^{13}$ tiene carácter subjetivo, es decir, está vinculada a la persona concreta $^{14}$, y lo que se persigue es, además de impedir que una persona se petrifique en el Tribunal, evitar las tentaciones de algún juez de «tratar de agradar» con su actuación a aquella

13 Un punto polémico al respecto ha sido el del cómputo del plazo que un magistrado debe esperar para volver a ser reelegido — asunto que, como el lector habrá advertido, no ha sido previsto por la LOTC- Sobre esta cuestión la doctrina se encuentra dividida, pues la LOTC contempla dos tipos de períodos, los de nueve años - mandato- y los de tres — renovaciones parciales- Sobre la interpretación favorable a los tres años, véanse Espín Templado (200r: 300-301) y Fernández Segado (1999: 123). Acerca de la interpretación favorable a los nueve años, véanse De Esteban y González Trevijano (1994: 183) y Lozano Miralles y Saccomanno (2000: 193). En todo caso, y por lo que respecta a la realidad práctica, solo un magistrado del Tribunal Constitucional ha formado parte del colegio en dos ocasiones diferentes. Se trata de D. Javier Delgado Barrio, quien fue parte del órgano entre 1995 y 1996, momento en que renunció para incorporarse como presidente del Consejo General del Poder Judicial y del Tribunal Supremo, volviendo a la magistratura constitucional en el año 2001.

Siendo indiferente que la reelección pudiera provenir de un órgano diferente a aquel que inicialmente propuso al referido magistrado. $C f$ r. Fernández Segado (1999: 122). El autor aclara en una nota al pie que esta duda interpretativa solo puede darse respecto de las propuestas que corresponden al Gobierno y al Consejo General del Poder Judicial. Pues, lógicamente, cuando la renovación afecta a los otros tercios, cesan unos magistrados que han sido propuestos por el mismo órgano que ahora debe efectuar la renovación. Con lo cual, no cabe plantearse la pregunta (Fernández Segado incluye la garantía de la irreelegibilidad inmediata dentro de los llamados «frenos frente a la politización»). 
fuerza política que avaló su candidatura, con el fin de poder renovar en el cargo (Espín Templado, 2001: 300). Así, podemos decir que esta garantía trata de cumplir con dos objetivos: por un lado, tiene como finalidad proteger la independencia de los magistrados (rompiendo cualquier atadura política con el objetivo de alcanzar la reelección), y, por el otro, tiende a facilitar la continuidad y la estabilidad en el seno del Tribunal. En este sentido, el legislador orgánico ha optado por una solución moderada, ya que prescribe una limitación parcial a la posibilidad de repetir en el cargo, $y$, al mismo tiempo, favorece la permanencia de aquellos miembros cuya estancia haya sido particularmente breve.

En lo que atañe a la renovación del Tribunal Constitucional el art. 159. $3 \mathrm{CE}$ nos indica que los magistrados «se renovarán por terceras partes cada tres [años]». Al respecto, el art. 16. 3 LOTC no aporta nada nuevo, ya que se limita a reiterar la previsión constitucional. La opción por un sistema de renovación parcial se configura como otra de las garantías tendentes a preservar la independencia del Tribunal, y es por ello que se ha ganado el beneplácito de la doctrina.

De tal manera, la garantía de la renovación parcial actúa como matiz o contrapeso de lo dicho hace un momento al referirme al prolongado mandato de los jueces constitucionales. De un lado favorece la estabilidad y la unidad de la doctrina del Tribunal (Alzaga Villaamil, 1978: 921) (frente a un modelo de sustitución simultánea), pero, al mismo tiempo, evita el anquilosamiento de su jurisprudencia, asegurando su progresivo aggiornamento (Almagro Nosete, 1989: 107).

El constituyente, consciente de la imposibilidad material de conciliar la exigencia del mandato de nueve años con la renovación parcial por tercios en el caso de la primera integración del Tribunal Constitucional — aquella de 1980_, dada la entrada simultánea de todos sus miembros, estableció un régimen transitorio (disposición transitoria novena $\mathrm{CE}$ ) en los siguientes términos:

A los tres años de la elección por vez primera de los miembros del Tribunal Constitucional, se procederá por sorteo para la designación de un grupo de cuatro miembros de la misma procedencia electiva que haya de cesar y renovarse. A estos solos efectos se entenderán agrupados como miembros de la misma procedencia a los dos designados a propuesta del Gobierno y a los dos que proceden de la formulada por el Consejo General del Poder Judicial. Del mismo modo se procederá transcurridos otros tres años entre los dos grupos no afectados por el sorteo anterior. A partir de entonces se estará a lo establecido en el número 3 del art. $159^{15}$.

15 Para una comprensión global de este mecanismo conviene recordar el contenido de la disposición transitoria tercera, apartado $2 .^{\circ}$, de la LOTC, que añadió: «No será 
Por lo que respecta a la finalización del mandato, el art. 159 CE en su apartado 5 establece un estatuto jurídico al que los jueces constitucionales deberán estar sometidos con la finalidad de proteger su independencia $-\mathrm{y}$, por ende, su imparcialidad-: «[...] los miembros del Tribunal Constitucional serán independientes e inamovibles en el ejercicio de su cargo». Disposición que debe ser interpretada en conexión con los arts. 23 y 24 LOTC para comprender las restringidas condiciones de cese y suspensión de los magistrados constitucionales.

La inamovilidad, recordemos, es una de las garantías clásicas de la independencia judicial, consistente en un medio de resistencia frente al Poder Ejecutivo. Esta salvaguarda, también aplicable al caso de los jueces constitucionales, presenta una doble proyección: evita que los órganos que designan a los miembros del Tribunal Constitucional puedan posteriormente removerlos del cargo y tiende a crear un espacio profesional sereno en el que el juez pueda desarrollar su labor de enjuiciamiento (Lozano Miralles y Saccommano, 2000: 199).

En este orden de cosas, el principio de inamovilidad exige que los magistrados constitucionales no puedan ser removidos o apartados del cargo, si no es por alguna de las causas previstas legalmente (arts. 23 y 24 LOTC). Además de la expiración del mandato, los supuestos a los que nos podemos enfrentar en la práctica —art. 23 LOTC— pueden clasificarse del modo que sigue:

a) Causas involuntarias: incapacidad intelectual o física sobrevenida que inhabilite para el desempeño del cargo — aplicabilidad de las causas de incapacitación que rigen para los miembros del Poder Judicial (art. 303 de la Ley Orgánica del Poder Judicial, de 1 de julio de 1985)—o fallecimiento - es más propiamente un caso de vacancia-

b) Causa derivada de conducta lícita: renuncia al cargo. Su eficacia está condicionada a la aceptación por el presidente. En cualquier caso, para este la aceptación de la dimisión es a priori un acto obligado, y no discrecional, pues sería absurdo mantener en el cargo a un magistrado en contra de su voluntad. Sin perjuicio de que aquel pueda modular los

aplicable la limitación establecida en el art. 16. 2 de esta Ley —actualmente el 16. 4, que limita la posibilidad de reelección inmediata; vid. supra- a los Magistrados del Tribunal que cesaran en sus cargos, en virtud de lo establecido en la disposición transitoria novena de la Constitución, a los tres años de su designación». 
efectos temporales de la renuncia si se considerase necesario atendiendo a razones de organización interna del Tribunal ${ }^{16}$.

c) Causas derivadas de conductas ilícitas: incompatibilidad sobrevenida; falta de diligencia en el cumplimiento de los deberes del cargo; violación de la reserva propia de la función, y sentencia de condena por delito o por incurrir en responsabilidad dolosa - basta la condena en cualquier instancia, no se exige que sea firme; incluye las infracciones y delitos cometidos fuera del ejercicio de cargo-—.

Por lo que respecta a Italia en materia de mandato de los magistrados constitucionales, debe abordarse su estudio diferenciando la regulación actual de aquella previa a la Ley Constitucional número 2 de 22 de noviembre de 1967. Esta reforma constitucional marcó en su momento un punto de inflexión en la manera de concebir los esquemas de permanencia y renovación en el seno de la Corte Constitucional. Podría pensarse que en nuestros días poco sentido tiene aludir a un modelo de mandato derogado hace cincuenta años, pero este cobra especial interés al tratar de establecer un estudio comparativo con España. Pues, como se verá a continuación, las similitudes del art. $135 \mathrm{CI}$ en su redacción original con las previsiones del art. 159. 3 CE son más que elocuentes.

El art. 135 coma 3 de la Constitución Italiana en su redacción primigenia establecía lo siguiente: «[...] i giudici sono nominati per dodici anni, si rinnovano parcialmente secondo le norme stbilite dalla legge e non sono inmediatamente rieleggibili».

En términos similares a los previstos en el ordenamiento constitucional español, el constituyente italiano ya en 1947 positivizó, y nada menos que con rango constitucional - con lo que ello supone de indisponibilidad para el legislador ordinario-, la duración en el cargo de los llamados a integrar la futura Corte Constitucional. Estableciendo un mandato prolongado en el tiempo de doce años, siguiendo así el ejemplo alemán.

En cuanto a la renovación se optó por un mecanismo de sustitución parcial, cuyo desarrollo vendría determinado en un momento sucesivo por la Ley Constitucional número 1 de 11 de marzo de 1953, cuyo art. 4 - posteriormente derogado en 1967- confirmaba la duración de doce años y concretaba las previsiones constitucionales de la renovación de la siguiente manera:

16 Baste como ejemplo lo sucedido en junio de 2011 con ocasión de la dimisión de tres magistrados cuyo mandato había expirado y pretendían de ese modo forzar su renovación. El presidente del Tribunal Constitucional no aceptó las renuncias. 
[...] i giudici che sono nominati alla scadenza dei dodici anni dalla prima formazione della Corte $^{17}$ si rinnovano, decorsi nove anni, mediante sorteggio di due giudici tra quelli nominati dal Presidente della Repubblica, di due tra quelli nominati dal Parlamento e di due tra quelli nominati dalle supreme magistrature ordinaria ed amministrativa [...]. Decorsi i altri tre anni, si rinnovano i giudici che non sono stati rinnovati. Successivamente si rinnovano ongi nove anni i giudici rimasti in carica dodici anni. In caso di vacanza dovuta alla scadenza del termine di dodici anni o ad altra causa la sostituzione avviene entro un mese della vacanza stessa ${ }^{18}$.

La introducción de este esquema normativo, a pesar de su capacidad teórica para solventar las imprecisiones del constituyente en su regulación inicial de esta materia, se topó de bruces con la realidad, y por ello la posterior Ley Constitucional número 2 de 22 de noviembre de 1967, supuso un cambio radical en la regulación del mandato de los jueces de la Corte Constitucional italiana en su dimensión temporal. Las novedades respecto al esquema referido pueden advertirse de la simple lectura del art. 135 comas 3 y 4 CI en su subsiguiente redacción: «[...] i guidici della Corte Costituzionale sono nominati per nove anni, decorrenti per ciascuno di essi dal giorno del giuramento, e non possono essere nuovamente nominati. Alla scadenza del termine il giudice costituzionale cessa dalla carica e dall'esecizio delle funzioni».

Del precepto extraemos cuatro consecuencias: el acortamiento del mandato de doce a nueve años - lo que lo aleja del modelo alemán y anticipa así la posterior regulación española-; la superación de la renovación parcial anteriormente descrita establecida en 1953, y su sustitución por un mecanismo de renovación gradual basado en el cumplimiento efectivo del mandato personal por parte de todos los jueces desde el momento de la toma de posesión; la prohibición de la reelección en todo caso —a diferencia de la limitación

17 El contenido del art. 135 CI para su correcta interpretación debía completarse con lo previsto en la disposición transitoria VII coma 3, que rezaba: «[...] i giudici della Corte costituzionale nominati nella prima composizione della Corte stessa non sono soggetti alla parziale rinnovazione e durano in carica dodici anni».

18 El establecimiento de un mecanismo de sorteo que permitiese hacer compatible la exigencia de la renovación parcial con la fijación del mandato en doce años en la coyuntura de la primera composición de la Corte, que suponía el acceso contemporáneo de los jueces al órgano; recuerda en gran medida al contenido de la disposición transitoria novena CE — vid. supra_-, dirigida a solventar esta misma situación en el caso español. 
previa que se circunscribía a la confirmación inmediata-, y la interdicción de la prorogatio ${ }^{19}$ como mecanismo facilitador de la continuidad de las funciones.

Aunque la Constitución guarda silencio al respecto, los jueces de la Corte Constitucional gozan, del mismo modo que sus homólogos españoles, de la garantía que supone la prerrogativa de inamovilidad como mecanismo protector de la independencia judicial por antonomasia. Así viene determinado tempranamente en el art. 3 coma 2 -actualmente coma 1, tras la reforma operada por la Ley Constitucional número 2 de 22 de noviembre de $1967-$ de la Ley Constitucional número 1 de 9 de febrero de 1948, que dice así: «[...] i giudici della Corte Costituzionale non possono essere rimossi, né sospesi dal loro ufficio se non con decisione della Corte [...]». Precepto cuya interpretación sistemática a la luz del art. 8 de la Ley Constitucional número 1 de 11 de marzo de 1953, y el art. 17 del Reglamento General de la propia Corte, de 20 de enero de 1966, compone el marco normativo de las posibles causas de cese anticipado en que pueden incurrir los jueces constitucionales. Siguiendo el esquema trazado para el caso español podemos dividirlas en las siguientes categorías:

a) Causas involuntarias: incapacidad física sobrevenida (art. 3 coma 1 Ley Constitucional n. 1 de 1948). Debiendo entenderse por tal solo aquellos impedimentos de carácter definitivo y permanente, que como consecuencia de dicha naturaleza constituyen una imposibilidad absoluta de volver a desempeñar el cargo en un período inferior a los seis meses ${ }^{20}$.

b) Causa derivada de conducta lícita: dimisión (art. 17 del Reglamento General de la CC).

c) Causas derivadas de conductas ilícitas: incapacidad civil sobrevenida (art. 3 coma 1 Ley Constitucional n. 1 de 1948), consiguiente a la declaración de prohibición e inhabilitación resultante de una sentencia condenatoria sobrevenida como consecuencia de un procedimiento civil o penal; «graves faltas» en el ejercicio de las funciones inherentes al cargo (mismo precepto que en la causa anterior), concepto jurídico indeterminado que

19 El instituto de la prorogatio en el ordenamiento italiano - a pesar del silencio del constituyente y del legislador al respecto- había sido introducido en 1966 por la propia Corte Constitucional en ejercicio de su potestad de autonormación, a través del art. 18 de su Reglamento General.

20 Esta interpretación es la efectuada por Giustino D’Orazio, quien analiza la disposición referida en atención a la previsión del art. 8 de la Ley Constitucional n. 1 de 1953, que establece como motivo de cese en el cargo la inactividad prolongada de un magistrado. Para este autor, esta norma establece una protección de la titularidad del puesto a favor del impedido por un plazo de seis meses (D’Orazio, I966: 171-173). 
ofrece un amplio margen de discrecionalidad en su valoración por la propia CC, que debe entenderse referido en todo caso a aspectos como obligaciones de naturaleza funcional, prohibiciones concretas, incompatibilidades sobrevenidas o, más en general, principios de corrección deducibles de la especial naturaleza de las funciones atribuidas al órgano (D’Orazio, 1966: 175 y ss.), y no desempeño de la labor de juez constitucional por un período de seis meses (art. 8 Ley Constitucional número 1 de 11 de marzo de 1953).

En sendos ordenamientos la finalidad última de las estipulaciones temporales no es otra que garantizar de la mejor manera posible la independencia de los jueces en su labor de máximos intérpretes del Texto Fundamental, sin olvidar las debidas exigencias de estabilidad en un órgano cuyas atribuciones son especialmente relevantes.

Desde el punto de vista patológico, podemos señalar como principales fenómenos los prolongados retrasos parlamentarios en la integración de las vacantes correspondientes a su turno, las ventajas y desventajas de instituciones como la prorogatio, así como los inconvenientes derivados de la renovación escalonada en determinados supuestos, es decir, la contradicción eventual entre el cumplimiento efectivo del mandato personal de nueve años y la debida cadencia de los tercios. Cuestiones todas ellas muy ligadas a lo apuntado en el apartado anterior, en la medida en que las previsiones relativas a la duración del mandato coadyuvan a construir una esfera libre de injerencias en el desempeño del cargo en favor de los jueces constitucionales.

En cuanto a la regulación de la duración del mandato en Italia, muestro mi preferencia por el modelo construido a partir de la reforma constitucional de 1967. Considero que la fijación de nueve años es apropiada, en la medida en que supone un período suficientemente prolongado como para alejarse de la lógica de las legislaturas y que, al mismo tiempo, frente a los doce años del diseño anterior, evita el anquilosamiento de la Corte Constitucional como consecuencia de permanencias excesivamente dilatadas en el cargo —a lo que se suma, además, la correspondiente prohibición de reelección-. Asimismo, debe considerarse digna de consideración positiva la abolición de la renovación parcial en favor del agotamiento del mandato individual como criterio para la asignación de los puestos vacantes. Las ventajas de esta opción, tomando en consideración la garantía de independencia del magistrado, se unen a su virtualidad como mecanismo desincentivador de la lotizzazione como instrumento preferente en la negociación de las candidaturas por parte de los órganos proponentes. El escalonamiento en las sustituciones obstaculiza esta praxis perniciosa, obligando a las fuerzas políticas a llegar a soluciones de compromiso aceptables por todos. En consecuencia, valoro positivamente la 
exclusión de la prorogatio, cuyas consecuencias negativas — que no niegoson menos acentuadas que en un modelo de renovación simultánea. Si bien tal prohibición de continuidad de las funciones no ha conseguido los efectos deseados como estímulo al Parlamento para la pronta selección de los jueces salientes, no es menos cierto que su operatividad alentaría aún más tales incumplimientos y situaría a los magistrados prorrogados - y por extensión a todo el órgano- en una situación de interinidad que comprometería su credibilidad hacia el exterior. En este sentido, creo que la única solución razonable al problema de los retrasos parlamentarios es precisamente la apelación al sentido de Estado y su concreción a través del principio de lealtad institucional, y soy también favorable a la introducción de sanciones de tipo institucional como salvaguarda frente a situaciones límite (como el bloqueo del año 2002 o una hipotética reedición de lo acontecido con l'Alta Corte per la Regione Sicilia y su desintegración). La cooptación en favor de la Corte Constitucional o la atribución de los nombramientos al jefe del Estado serían medidas dignas de ser tomadas en consideración.

Por lo que respecta a España, y en línea con lo señalado previamente, sería deseable una reforma constitucional radical, que se acercase a los criterios temporales establecidos por el constituyente italiano en 1967. Si bien es cierto que el modelo italiano no resuelve por completo determinados problemas compartidos por el esquema español, la comparación demuestra que las fórmulas mágicas no existen y que debemos tratar de adaptar lo mejor posible a cada contexto las experiencias que han obtenido un mejor desempeño. Por tanto, creo que el ejemplo italiano — basado en la primacía del mandato individual — es más coherente con la garantía de independencia de los jueces constitucionales (y su igual dignidad en el interior del órgano), y que, por ello, debe ser defendido ${ }^{21}$. Del mismo modo que en el caso de Italia, también en España, la solución a los retrasos parlamentarios depende en última instancia de la voluntad de los partidos políticos de cumplir con las obligaciones constitucionales que les son propias, y, por este motivo, critico severamente las dos últimas reformas llevadas a cabo por el legislador orgánico: la previsión de la prórroga del mandato presidencial y la fijación de un criterio de cobertura de vacantes basado en la prevalencia del mandato institucional. En dichas modificaciones, motivadas por una excepcional situación de falta de renovación de dos tercios del Tribunal Constitucional, el legislador orgánico optó por dar prioridad a la lógica de la confrontación partidista en detrimento de los

21 En España una firme posición en favor de la primacía del mandato individual frente a la inercia de los tercios puede encontrarse en el profesor Germán Fernández Farreres; por todas sus intervenciones al respecto, véase Fernández Farreres, 2015: 28 y ss. 
mandatos constitucionales del correcto funcionamiento de las instituciones, poniendo con ello en serio riesgo el propio Tribunal y su imagen. Una senda peligrosa para una institución cuya legitimidad debe quedar al margen de la controversia política, y que se podría evitar a través de una reforma constitucional que consolidase el agotamiento del mandato personal de nueve años por parte de los miembros del Tribunal Constitucional. Una revisión de la duración del mandato que debería ser completada — en el sentido ya indicado para Italia - con la introducción de un mecanismo subsidiario de cobertura de vacantes en el caso de que no se produzca la sustitución en tiempo de los magistrados salientes.

\section{PRERROGATIVAS Y RESTRICCIONES DERIVADAS DEL EJERCICIO DE LA MAGISTRATURA CONSTITUCIONAL}

Para finalizar con el análisis de los aspectos orgánicos del mandato de los jueces constitucionales, corresponde referirse al «estatuto jurídico» de estos, es decir, al conjunto de prerrogativas y restricciones que rodean su estancia en el órgano (y en algún caso más allá del cese). Todas ellas encaminadas a preservar un espacio de independencia, dignidad y responsabilidad para el ejercicio de las altas funciones encomendadas a los titulares de la Corte Constitucional y el Tribunal Constitucional respectivamente.

En el caso español, el hilo conductor a todas las restricciones y prerrogativas que señalaré a continuación viene determinado por el art. 159. $5 \mathrm{CE}$, posteriormente concretado a través del art. 22 LOTC. El contenido de ambos preceptos es el que sigue:

Art. 159. 5 CE: Los miembros del Tribunal Constitucional serán independientes e inamovibles en el ejercicio de su mandato.

Art. 22 LOTC: Los Magistrados del Tribunal Constitucional ejercerán su función de acuerdo con los principios de imparcialidad y dignidad inherentes a la misma; no podrán ser perseguidos por las opiniones expresadas en el ejercicio de sus funciones; serán inamovibles y no podrán ser destituidos ni suspendidos sino por alguna de las causas que esta Ley establece.

De la lectura de estos dos artículos pueden extraerse tres principios generales:

a) Principio de independencia: se configura como el principio básico en torno al cual se ha construido todo el estatuto de los jueces constitucionales. 
Es una condición consustancial a toda función jurisdiccional. Íntimamente ligado con este principio se encuentra el principio de imparcialidad. Las garantías que examinaremos en este capítulo están orientadas a hacer efectiva la independencia de los jueces constitucionales, cuya finalidad última es conseguir que estos ejerzan su función de acuerdo con el principio de imparcialidad. Independencia e imparcialidad son principios distintos pero complementarios, que han sido distinguidos por la doctrina procesalista atendiendo a la dualidad potestadlfunción. La independencia se conectaría con la potestad jurisdiccional, mientras que la imparcialidad sería predicable del ejercicio concreto de la función jurisdiccional. Es más, podría decirse que la independencia y la imparcialidad se diferencian fundamentalmente por tener distintos momentos de aplicación. Mientras que la primera hace referencia al momento constitucional, la segunda viene ligada al momento procesal. Siendo en todo caso la independencia presupuesto e instrumento de la imparcialidad, necesario, pero no suficiente (Jiménez Asensio, 2002: 69-70). En resumen, la independencia proclamada respecto de los miembros del Tribunal Constitucional no constituye un fin en sí misma; sino que la independencia es el instrumento a través del cual la función jurisdiccional puede realizarse imparcialmente (Espín Templado, 2001: 338). La independencia presenta tres proyecciones:

a.1) Independencia frente a los demás poderes públicos: aquí se insertarían las prerrogativas de la inamovilidad (causas de cese y suspensión) ${ }^{22}$ y la inviolabilidad (arts. 22, 23 y 24 LOTC).

a.2) Independencia frente a las partes: se logra con un estricto régimen de incompatibilidades (arts. 159. 4 CE y 19 LOTC) y con las instituciones del deber de abstención, y el derecho de recusación (art. 80 LOTC, que remite a los arts. 217 y ss. LOPJ y 99 y ss. LEC).

22 Sobre la importancia de la inamovilidad, debe destacarse la STC 47/2011, de 12 de abril, en cuyo FJ 6 el Tribunal Constitucional señala: «[...] la independencia e inamovilidad de los miembros del Tribunal Constitucional en el ejercicio de su mandato es una de las garantías expresamente previstas en el art. 159.5 CE. Las eventuales causas de cese de un Magistrado del Tribunal Constitucional tienen una indudable conexión con el ejercicio independiente de la función jurisdiccional de los miembros del Tribunal Constitucional, toda vez que afectan a la conformación misma del órgano y al sistema de equilibrios que para la elección de los Magistrados del Tribunal Constitucional se establece en los apartados 1 y 3 del art. 159 CE». 
a.3) Independencia dentro del órgano: se materializa en la formulación de votos particulares (Lapuente Aragó, 1997: 438-442) (arts. 164. 1 CE y 90. 2 LOTC).

b) Principio de dignidad: se trata de un atributo honorífico mediante el cual el legislador ha querido subrayar la relevancia institucional de la tarea que la Constitución ha encomendado al Tribunal Constitucional (Espín Templado, 2001: 337). La concreción de este principio podemos encontrarla en una serie de derechos y deberes de los jueces constitucionales, a saber: el derecho a la retribución económica y otras cuestiones de índole laboral (situación de servicios especiales a favor de los funcionarios y cómputo del mandato a efectos pasivos) (Presupuestos Generales del Estado y arts. 20 y 25 LOTC), el derecho a ostentar la condición de magistrado emérito (arts. 41 y 42 del Reglamento de Organización y Personal del Tribunal Constitucional - ROP-), el privilegio del fuero (arts. 26 LOTC y 56. 2 LOPJ), el deber de diligencia y el deber de reserva o sigilo (art. 23. 1 LOTC).

c) Principio de responsabilidad: es el correlato lógico al principio de independencia. Respecto de los magistrados constitucionales podemos llegar a predicar tres tipos de responsabilidad: la penal, la civil y la disciplinaria (arts. 15 y 26 LOTC, 56.2 LOPJ y 14.j ROP).

El esquema italiano de garantías de independencia de los jueces constitucionales presenta ciertos paralelismos con el español. Pudiendo esquematizarse así:

- Restricciones: régimen de incompatibilidades (arts. 135.6. CI y arts. 7 y 8 de la Ley número 87, de 11 de marzo de 1953); abstención y recusación (no aplicación en los procedimientos constitucionales, aunque existe el mecanismo corrector del «legítimo impedimento», art. 29 de las Normas Complementarias para los juicios ante la Corte Constitucional, de 7 de octubre de 2008, y art. 16.1 de la Ley número 87).

- Prerrogativas: inamovilidad (art. 3.1 de la Ley Constitucional número 1 de 1948, además del art. 7 de la Ley Constitucional número 1 de 1953, y cabe destacar el supuesto de remoción por abandono voluntario de tareas por un período de seis meses, previsto en el art. 8 de la Ley Constitucional número 1 de 1953), inviolabilidad (art. 5 de la Ley Constitucional número 1 de 1953, aunque en este punto debe recordarse que en Italia no está previsto el dissent, por lo que es difícil conocer las opiniones y votos individuales de cada juez constitucional), no persecución por acciones penales (reenvío establecido en el art. 3 de la Ley Constitucional 
número 1 de 1948), retribución económica (art. 6 de la Ley Constitucional número 1 de 1953 y art. 19 del Reglamento General de la Corte Constitucional, de 20 de enero de 1966), derechos honoríficos (arts. 20 y 21 del Reglamento General de la Corte).

Desde el punto de vista patológico, podemos identificar tres bloques de problemas. El primero, relativo a los magistrados constitucionales y su libertad de expresión, donde se cuestionaría: el poder de «exteriorización» de los presidentes de los órganos de Justicia constitucional y sus límites, su conexión con la idoneidad de la aplicación de las categorías de abstención y recusación y la debida interpretación de sus causas, las restricciones a la militancia en partidos políticos y su vínculo con la apariencia de imparcialidad, y, por último, las ventajas e inconvenientes de la figura del voto particular.

Un segundo bloque referido a los magistrados constitucionales ante la acción de la Justicia, donde podrían criticarse prerrogativas como el fuero especial español o la autorización para proceder italiana, y donde también cabría reflexionar acerca de la responsabilidad civil de los magistrados en el ejercicio de sus funciones y su intrínseca relación con la prohibición de fiscalización de la actuación de los órganos de Justicia constitucional: la guerra delle due Corti.

Un tercer y último bloque relativo a la finalización del mandato abarcaría la referencia a los casos de dimisión y el tratamiento que estos deben recibir, así como a las dificultades en términos de independencia que puede plantear el futuro profesional de los magistrados salientes.

Entrando en el fondo del estatuto jurídico de los magistrados constitucionales, por lo que respecta a sus límites a su libertad de expresión y, más concretamente, al poder de exteriorización atribuido al presidente, planteo la posibilidad de trabajar en una suerte de política comunicativa propia del órgano que derive en un mejor conocimiento del mismo por parte de la sociedad. Una estrategia de comunicación consensuada entre los miembros del colegio, de modo que el titular de la Presidencia se transforme en la imagen de la institución, explicando a la ciudadanía el trabajo que se realiza en el interior de la misma. Rechazo, sin embargo, las experiencias negativas en las que los titulares de la Presidencia han puesto en duda su condición, expresando públicamente pensamientos y posiciones estrictamente personales respecto de situaciones de la vida política —susceptibles, incluso, de ser objeto de un procedimiento constitucional—, comprometiendo, así, su debida imparcialidad.

Por lo que respecta a las causas de abstención y de recusación, y a pesar de lo acaecido en los últimos años en el contexto español, considero necesaria su existencia. Porque, si bien en general los procedimientos constitucionales se caracterizan por una mayor abstracción y generalidad respecto de aquellos otros de la jurisdicción ordinaria, es también cierto que pueden 
darse situaciones en que existan conflictos de intereses entre uno de los jueces individualmente considerado y las partes o el objeto de la controversia. Me posiciono, por tanto, en favor de su introducción en el ordenamiento italiano.

No obstante, la experiencia española en atención a lo sucedido con el polémico ATC 26/2007 debe servir como ejemplo de mala praxis en la interpretación de las causas de recusación. Como aprendizaje debe extraerse la necesidad de tener en cuenta la excepcionalidad de estas figuras y la necesidad de interpretación restrictiva de las mismas como garantía de la independencia del colegio a resguardo de los abusos de las fuerzas políticas.

A propósito de lo dicho en líneas precedentes, considero necesario aclarar - mediante un cambio normativo en el caso español y una amplia interpretación en el italiano- la debida incompatibilidad de la militancia política con el ejercicio de las funciones de magistrado constitucional. Es por ello que no comparto la reiterada jurisprudencia del Tribunal Constitucional en la materia, pues, en mi opinión, la existencia de un vínculo formal con los partidos distorsiona la imagen de imparcialidad que debe acompañar a los miembros del órgano de cierre del sistema.

Siguiendo con mi posición en pos de la creación de órganos de Justicia constitucional transparentes y abiertos al diálogo con los cuidadanos, soy decididamente favorable a la recepción en el modelo italiano de la figura del voto particular. Considerando su potencialidad en términos de control democrático de las decisiones, así como de incentivo de una jurisprudencia en constante evolución, el acercamiento al ordenamiento español en este aspecto me parece una propuesta adecuada.

Con respecto a las prerrogativas de los magistrados frente a la acción de la Justicia —el fuero especial y la autorización para proceder penalmente respectivamente- considero que ha llegado el momento de reconsiderar el mantenimiento de tales figuras. Su quiebra con el principio de igualdad, así como el riesgo de abusos, me permite pedir su abolición. Superados los momentos iniciales de actuación de la Constitución y consolidadas ya las democracias española e italiana, no debe seguirse desconfiando del criterio de los jueces ordinarios en la persecución de las conductas de aquellos.

Dicho esto, sin embargo, debe llamarse la atención sobre el peligroso precedente del Tribunal Supremo español de 2004 (STS Sala Primera, de 23 de enero de 2004), según el cual, mediante el genérico recurso a la responsabilidad civil por daños, fueron condenados once miembros del Tribunal Constitucional. Ello supuso la revisión de una decisión previa del órgano de cierre, lo que generó una grave crisis institucional de la que deben ex- 
traerse consecuencias para el futuro ${ }^{23}$. Si, de un lado, debemos reconocer la posibilidad de exigir responsabilidad civil a los miembros del Alto Tribunal, también debemos señalar que este es el supremo en materia de garantías constitucionales y que su jurisdicción no puede ser puesta en discusión por ningún otro poder del Estado. De tal manera, una correcta relación entre jurisdicción constitucional y jurisdicción ordinaria requiere un esfuerzo por parte de los actores implicados en delimitar de la manera más escrupulosa posible sus respectivas esferas competenciales, y — consideradas las dificultades prácticas de tal delimitación - reclamar en última instancia la moderación de estos en su proceder.

Para finalizar, y por lo que se refiere a la conclusión del mandato de los magistrados constitucionales, es indispensable hacer dos precisiones. En primer lugar, considero necesario señalar la particular atención que deben requerir los casos de dimisión en ausencia de causas justificadas de tipo objetivo e indiscutible. Los riesgos de que la renuncia sea utilizada como instrumento para alterar de modo consciente la composición del colegio, modificando la cadencia natural de los tiempos de renovación, exigen una ponderación de los intereses antes de pronunciar su aceptación. Unas consideraciones que también permiten sostener la necesidad, en su caso, de establecer condiciones que modulen los efectos temporales de salida del órgano, si la situación organizativa así lo requiriese.

En segundo lugar, propongo la introducción de la situación de los magistrados salientes en el más amplio debate sobre las "puertas giratorias». Es decir, considero oportuno que, en el caso de que se establezcan normativas de alcance general sobre incompatibilidades posfuncionales en relación con cargos representativos o de designación política, también los miembros de los órganos de Justicia constitucional estén sometidos a tales limitaciones. La imposibilidad de ejercer el propio mandato con la expectativa de «hacer carrera" posteriormente abre un escenario más propicio para la independencia en la toma de decisiones. Lejos de las tentaciones de una recompensa futura.

23 Una vía de solución puede encontrarse en la nueva redacción del art. 4 de la LOTC, tras la reforma operada por la LO 6/2007. Así, la modificación del precepto, que tuvo por finalidad otorgar un mayor peso institucional al Tribunal Constitucional, puede resumirse de forma esquemática en tres premisas: autodelimitación de la propia jurisdicción, potestad anulatoria sobre todas aquellas resoluciones que la menoscaben y no enjuiciabilidad de las resoluciones del Tribunal Constitucional por ningún otro órgano jurisdiccional del Estado. 


\section{CONCLUSIONES}

A todo lo dicho anteriormente, simplemente añadir la necesidad de enfatizar la dimensión técnico-jurisdiccional de los órganos de Justicia constitucional, sin que ello comporte la negación de la relevancia política de su función. De modo que, más que proponer cambios legislativos — que también-, lo más realista en este punto es apelar a los partidos a operar de acuerdo con el principio de lealtad institucional y a actuar con altura de miras. Además, y teniendo en cuenta el nuevo contexto político, caracterizado por la presencia de más partidos en el arco parlamentario, será imprescindible redoblar los esfuerzos por forjar consensos a falta de las amplias mayorías del pasado.

En pocas palabras, más allá de las fortalezas y debilidades de cada ordenamiento en la materia objeto de estudio, lo importante es evitar caer en la tentación de anteponer la dinámica de la realidad política a las necesidades inherentes al correcto funcionamiento del órgano encargado de ejercer la jurisdicción constitucional.

Y por lo que respecta a las prerrogativas propias del estatuto personal de los magistrados, debe recordarse que tienen la finalidad de garantizar su independencia y su imparcialidad, pero no es menos cierto que su naturaleza es contraria al principio de igualdad, lo que implica una interpretación restrictiva de las mismas con el ánimo de impedir que se transformen en privilegios en favor de una élite.

\section{Bibliografía}

Adamo, U. (2014). Breve nota sulla tempistica che ha guidato il Presidente della Repubblica a nominare i due giudici della Corte Costituzionale. Osservatorio Costituzionale, Associazione Italiana dei Costituzionalisti, 3, 1-7.

Almagro Nosete, J. (1989). Justicia Constitucional. Comentarios a la Ley Orgánica del Tribunal Constitucional. Valencia: Tirant Lo Blanch.

Aloisio, S. (2004). Considerazioni sui giudici costituzionali eletti dalle supreme magistrature. En A. Anzon, G. Azzariti y M. Luciani (eds.). La composizione della Corte Costituzionale. Situazione italiana ed esperienze straniere (pp. 181-198). Torino: Giappichelli.

Alzaga Villaamil, O. (1978). La constitución española de 1978 (Comentario sistemático). Madrid: Ediciones del Foro.

Baamonde Gómez, L. (2019). La magistratura constitucional en España e Italia. Selección, aspectos temporales del mandato y estatuto jurídico. Madrid: Centro de Estudios Políticos y Constitucionales.

D’Orazio, G. (s. f.). Prorogatio, supplenza, nomina di giudici costituzionali e continuità funzionale della Corte. Osservazioni. Attualità, Rassegna Parlamentare. 
- (1966). Aspetti dello status di giudice della Corte Costituzionale. Milano: Giuffrè.

De Esteban, J. y González Trevijano, P. J. (1994). Curso de Derecho Constitucional Español III. Madrid: Universidad Complutense de Madrid.

Espín Templado, E. (2001). Comentario del art. 16 LOTC. En J. L. Requejo Pagés (coord.). Comentarios a la LOTC (pp. 293-304). Madrid: Tribunal Constitucional; Boletín Oficial del Estado.

- (2001). Comentario del art. 22 LOTC. En J. L. Requejo Pagés (coord.). Comentarios a la LOTC (pp. 335-341). Madrid: Tribunal Constitucional; Boletín Oficial del Estado.

Fernández Farreres, G. (2015). Sobre la designación de los magistrados constitucionales: una propuesta de reforma constitucional. Revista Española de Derecho Constitucional, 105, 13-49.

Fernández Segado, F. (1999). Artículo 159. La composición del Tribunal Constitucional. En Ó. Alzaga Villaamil (dir.). Comentarios a la Constitución española de 1978 (pp. 61-172). Madrid: Cortes Generales; Editoriales de Derecho Reunidas.

García Pelayo, M. (1981). El status del Tribunal Constitucional. Revista Española de Derecho Constitucional, 1, 11-34.

Jiménez Asensio, R. (2002). Imparcialidad Judicial y Derecho al Juez Imparcial. Cizur Menor (Navarra): Aranzadi.

Lapuente Aragó, R. (1997). El estatuto de los magistrados del Tribunal Constitucional. En Estudios de Derecho Constitucional y de Ciencia Política. Homenaje al Profesor Fernández-Carvajal (vol. 1) (pp. 427-447). Murcia: Universidad de Murcia.

Lozano Miralles, J. y Saccomanno, A. (2000). El Tribunal Constitucional. Composición y principios jurídico-organizativos (el aspecto funcional). Valencia: Tirant lo Blanch.

Zagrebelsky, G. (1988). La Giustizia Costituzionale. Bolongna: Il Mulino. 